\title{
BRIEF
}

\section{Predictors of Academic Success in a Non-Traditional Doctor of Pharmacy Degree Program at a Historically Black College and University}

\author{
Youness R. Karodeh, PharmD, ${ }^{\mathrm{a}}$ LaMarcus Wingate, PharmD, PhD, ${ }^{\mathrm{a}}$ Imbi Drame, PharmD, ${ }^{\mathrm{a}}$ Patricia Y. Talbert, \\ $\mathrm{PhD}, \mathrm{MPH},{ }^{\mathrm{b}}$ Ashley Dike, PharmD, ${ }^{\mathrm{a}}$ Sophia Sin, PharmD ${ }^{\mathrm{a}}$ \\ ${ }^{a}$ Howard University, College of Pharmacy, Washington, DC \\ ${ }^{\mathrm{b}}$ Howard University, College of Nursing and Allied Health Sciences, Washington, DC
}

Corresponding Author: Youness R. Karodeh, Howard University, College of Pharmacy, $23004^{\text {th }}$ St NW, Washington, DC, 20059. Tel: 202-806-9076. Email: ykarodeh@howard.edu

Submitted February 18, 2021; accepted October 18, 2021; ePublished November 2021

\begin{abstract}
Objective. Rapid changes in the current U.S. health care system, especially in the fields of pharmacy and pharmaceutical sciences, require practicing pharmacists to acquire new knowledge and skills. Despite the growth of opportunities for pharmacists within new spaces such as nanotechnology, informatics, and pharmacogenomics, those without the Doctor of Pharmacy (PharmD) could be eliminated from consideration by employers who seek new graduates with more contemporary training and skills. The purpose of this study was to determine which associations exist between student success within the Non-Traditional Doctor of Pharmacy (NTDP) program and certain demographic factors.

Methods. This quantitative longitudinal study was designed to determine which factors predict academic success among NTDP students entering the College of Pharmacy. Academic success was measured by cumulative graduating grade point average (GPA). Data from four cohorts of students was utilized to develop multivariate linear regression models with several predictors including age, region of residence, citizenship status, previous pharmacy work background, and ethnicity.

Results. The study sample included 81 students and the mean cumulative GPA was 3.44. A foreign-born African heritage was predictive of a GPA that was significantly higher in comparison to African Americans after adjusting for other factors.

Conclusion. Findings showed that international students had a higher cumulative GPA in comparison to African American students in the NTDP program.

Keywords: non-traditional Doctor of Pharmacy, Doctor of Pharmacy degree (PharmD), academic success, Historically Black Colleges and Universities (HBCU)
\end{abstract}

\section{INTRODUCTION}

Although the number of colleges offering Doctor of Pharmacy (PharmD) programs for the working professional has been declining, evidence suggests that innovation and continuous program improvement are key to sustaining recruitment and maintaining successful program delivery in today's highly competitive market. ${ }^{1}$ This is attributable to the fact that recent changes in health care delivery have been spurred by systemic shifts. Such changes have required practicing pharmacists to acquire new knowledge and patient assessment skills in several areas. ${ }^{1,2}$

While opportunities for pharmacists are still growing, practicing pharmacists without a PharmD could face an unfavorable employment market should change of employment become desirable and/or necessary. Many entry level pharmacy positions now require applicants to have the PharmD degree, rather than a Bachelor of Science in Pharmacy or equivalent, and the PharmD is presently the only track offered for new graduates who enter the field within the United States (U.S.). ${ }^{3}$

Despite these dynamics, there exist only four U.S. institutions currently offering a nontraditional pathway for registered pharmacists to obtain the PharmD (down from 38 in 2002). ${ }^{4}$ These nontraditional degree programs (NTDP) were formed when the PharmD became the standard entry-level degree for those graduating from 2003 onward. These institutions have maintained their non-traditional programs largely because a reasonable applicant pool remains, with limited additional expenditures required by host institutions since there are "no separate accreditation requirements for nontraditional PharmD programs.",3,4

Each NTDP program, though similar in purpose, is structured differently in its requirements and delivery of didactic and experiential coursework. Accordingly, predictors of success may vary in NTDP programs, with schools serving a large proportion of racial and ethnic minorities exhibiting different predictors of success than majority institutions. Howard University College of Pharmacy offers a two-year NTDP program for U.S.- licensed pharmacists. 
The NTDP program has produced over 350 graduates in 19 cohorts since its inception in Fall 2003. Howard University is also the only Historically Black College and University (HBCU) currently offering a NTDP degree. The diversity of the program continues to be of interest to many perspective students globally. The purpose of this study was to evaluate factors which may predict the cumulative graduating grade point average (GPA) of students enrolled in a NTDP at a HBCU.

\section{METHODS}

A retrospective chart review was conducted by using the records for students entering the NTDP in successive cohorts from 2015 to 2019. The data was maintained as a part of quality control and the study was determined to be exempt by the Howard University Institutional Review Board. Individuals with complete admissions data were included. Individuals were excluded if they were dismissed from the program. The outcome was the student's cumulative graduating GPA in the pharmacy program and was measured as a continuous variable on a scale of one to four. All didactic courses taken during the first three semesters of the program contribute to student's GPA. The last semester consists of three experiential rotations which are pass/fail. Predictor variables included gender, ethnicity, region of residence within the U.S. while completing the program, residency status and previous type of pharmacy work experience. The region of residence in the U.S. while completing the program was categorized as either Midwest, Northeast, South, or West. The residency status was classified as a U.S. citizen or non-citizen. Pharmacy work experience was categorized as community, hospital, or other. Individuals not working at the time of program entry were placed into the unemployed category. The ethnicity considered whether the student was U.S. born or international. Accordingly, the ethnicity was categorized as African American (born in the U.S.), African (of African descent and international), Asian or White.

Descriptive statistics were conducted to characterize the nontraditional degree program participants. The independent samples t-test was, and one-way analysis of variance (ANOVA) were utilized to evaluate if there was a significant difference in the mean GPA by gender, residency status, ethnicity, type of previous pharmacy work experience, and age category.

Multivariate linear regression analysis was used to assess the independent effect of each of the predictor variables on the student's GPA after adjusting for other factors. The R square value was utilized to evaluate the fit of regression models. Statistical analyses were performed using SPSS and an alpha value of 0.05 was used to determine statistical significance.

\section{RESULTS}

The study included 81 students matriculating through the NTDP from 2015 to 2019 as seen in Table 1. The mean cumulative GPA was 3.44 ( $\mathrm{SD}=0.45)$. The students were nearly equally split between females $(52 \%)$ and males $(46 \%)$. The majority of students $(65 \%)$ resided in the Southern region of the U.S. while completing studies. Nearly half of the students (48\%) were African Americans. Just under 70\% of the students were U.S. citizens, and the most frequent type of pharmacy career that respondents were engaged in upon entering the program was community pharmacy (57\%).

As seen in Table 2, the mean cumulative GPA varied when it was evaluated across certain categories. The mean GPA of 3.31 in African American students was significantly lower than the mean GPA of 3.75 obtained by international Africans $(p<.05)$. There was also a significant difference in GPA by citizenship status $(p<.05)$, as the GPA of U.S. citizens (3.37) was lower than the GPA of students who were not U.S citizens (3.62). There were no other significant differences noted in the mean GPA in the bivariate analysis.

The R-square value of the multivariate linear regression model was 0.237 as depicted in Table 3 . In the multivariate linear regression analysis, international African heritage was predictive of a higher cumulative GPA in comparison to African Americans. More specifically, international African heritage was predictive of a GPA that was 0.39 points higher in comparison to African Americans after adjusting for gender, region of the U.S. the student lived in while completing the program, residency status, and previous type of pharmacy work experience $(p=.014)$. After adjusting for other factors, being a U.S. citizen was no longer predictive of a lower GPA. In the multivariate model, being a U.S. citizen was predictive of a GPA that was 0.22 points lower in comparison to non-citizens after adjusting for other factors $(p=.10)$.

\section{DISCUSSION}

The purpose of this study was to determine which associations exist between student success within the NTDP and demographic factors. Success in this study was measured by cumulative graduating GPA. One key correlation was discovered: though the majority of students enrolled in the NTDP program identified as African American and U.S.-born, being an international student who identified as African correlated with a higher graduating GPA. Students' place of residence, gender, and race appeared to serve as lesser predictors of success. 
The results of this study may reflect the sociodemographic dissections and paradoxes indicated by previous studies related to educational attainment amongst Black students within health care fields, most notably, gaps in academic achievement between African Americans and other students. ${ }^{5,6}$ In the medical field, Rao and Flores attribute achievement gaps to factors such as lack of family support and role models. ${ }^{8}$ According to Kent and colleagues, the number of Black immigrants to the U.S. has increased by more than 300 percent in the past three decades, ${ }^{9}$ with roughly $4 \%$ of Black immigrants being from the African continent and $9 \%$ being from the Caribbean. ${ }^{10,11}$ Chiswick and Miller highlight the fact that many African immigrants to the U.S. are highly skilled and highly educated due to the educational systems within their countries of origin. ${ }^{12}$ However, due to their racial minority status once in the U.S., African immigrants were more likely to experience career "mismatches" than other non-minority immigrant populations. This has placed many Africans in positions where their education level exceeded job qualifications. ${ }^{13,14}$

This historical phenomenon may explain trends prevalent within African immigrant populations today, which favor high educational and career attainment (degree-seeking). Literature reveals that many African immigrants may also be better-prepared for the rigorous math and science-based curricula of the PharmD program than U.S.-born students due to a "western trend" of selecting highly skilled international students for immigration. ${ }^{15,16}$ The combination of perceived need to obtain higher education to circumvent skills mismatches and strong baseline skills may explain why pharmacy represents a choice profession for many African immigrants, and why greater levels of academic success are achieved therein. Additionally, the field is often emphasized within their countries of origin, accompanied by more recent advocacy efforts to grow the profession within these countries. ${ }^{17}$ Nigeria, for example, has more pharmacy training programs than any other African nation with at least 17 schools currently offering a BPharm. Ethiopia has more than seven programs with at least two offering a master's degree. ${ }^{18}$ Efforts demonstrating a strong thrust toward the PharmD have been welldocumented in studies detailing the current state of the pharmacy profession within Ethiopia. ${ }^{19}$

At the other end of the spectrum, it is important to note that the academic performance of American-born Black student populations was lagging. Though not well-studied or articulated within the field of pharmacy education, this mirrors a larger national trend that shows that an achievement gap exists between African American students and other students possibly attributable to a lack of self-efficacy and early scientific exposure. ${ }^{6,20}$ Promising for programs such as NTDP, which utilize a distance learning platform, is the fact that distance learning programs may help to close the achievement gap between African American (AA) students and other students. ${ }^{6,21,22}$ Reasons cited are that AA students benefit from increased structure and inherent scheduling flexibility. Hybrid programs are cited as being the most beneficial option for AA students to make academic gains,${ }^{23}$ as regular virtual interaction with instructors appears to enhance academic confidence and self-efficacy amongst AA students. ${ }^{23,}{ }^{24}$ Limitations

Limitations of this study include the fact that investigators were not able to assess student motivations for enrollment in the NTDP program. This information may have helped to inform some of the demographic patterns observed within this study. The current study provides much needed additional information to the currently scarce body of literature which examines predictors of GPA among students in NTDP programs. ${ }^{24}$ There are potentially important variables that were not recorded in this analysis such as the number of years of prior experience the student had in pharmacy. However, GPA is a short-term measure of success in these adult learners so future studies should examine other outcomes which may be of even greater importance such as career trajectory. Moreover, because the sample included students from a single program, which primarily serves underrepresented students at a HBCU, study results may lack external validity. Recommendations for future study may therefore include exploring other NTDP programs to obtain more comprehensive data so that researchers can comparatively decipher trends and patterns related to student predictors of success.

\section{CONCLUSION}

As stated previously, the pharmacy profession is important on a societal level, particularly for communities of color. The NTDP program addresses the critical need for well-trained pharmacists by equipping a diverse cross-section of practicing pharmacists with new skills for serving present and future populations. This study investigated an area that currently lacks awareness and attention within pharmacy, factors that predict academic achievement within non-traditional degree programs. Findings revealed that international students had a higher cumulative GPA in comparison to African American students in the NTDP program. Methods for leveling student performance across demographic groups would be a worthwhile focus for future research.

\section{REFERENCES}


1. Cooper, JC, Li, H, Gharat, M, Khalifa, S. Clinical Pharmacy Education, Practice and Research: Clinical Pharmacy, Drug Information, Pharmacovigilance, Pharmacoeconomics and Clinical Research. 2009; Elsevier: Cambridge, MA, ISBN: 9780128142769

2. Teeraporn, S, Low, B, Wongpoowarak, P, Moolasarn, S, Anderson, C. A transition from the BPharm to the PharmD degree in five selected countries. Pharmacy Practice. 2019;17(3), 1611doi: 10.18549/PharmPract.2019.3.1611

3. Accreditation Council for Pharmaceutical Education; Declaration of intent: revision of accreditation standards in 1990's in keeping with changes in pharmacy practice and pharmaceutical education. Chicago: Accreditation Council for Pharmaceutical Education; 1989.

4. Prabhu S, Chung E, LeQA Nguyen M, and Robinson D. Process and Performance Outcomes of a Nontraditional Postbaccalaureate PharmD Program Geared Toward Internationally Trained Pharmacist. Am J Pharm Educ. 2015;79:8. doi:10.5688/ajpe798113

5. Beacham T, Askew RW, William PR. Strategies to increase racial/ethnic student participation in the nursing profession. Assoc of Black Nur Fac. 2009;20(3): 69-72.

6. Dotterer AM, Lowe K, McHale SM. Academic growth trajectories and family relationships among African American youth. $J$ Adol Res. 2014; 24(4):734-747. doi:10.1111/jora.12080

7. Rao V and Flores G. Why aren't there more African-American physicians? A qualitative study and exploratory inquiry of African-American students' perspectives on careers in medicine. JNat Med Assoc. 2007;99(9):986-993.

8. Kent MM. Immigration and America's black population. Population Bulletin. 2007;62(4). ISSN:0032-468X

9. Elo IT, Frankenberg E, Gansey R, Thomas D. Africans in the American labor market. Demography. 2015;52(5). doi: 10.1007/s13524-015-0417-y

10. Wafula EG and Snipes SA. Barriers to health care access faced by Black immigrants in the US: Theoretical considerations and recommendations. J Immigr Minor Health. 2014;16: 689-698. doi:10.1007/s10903-013-9898-1

11. Chiswick BR and Miller PW. Why is the payoff to schooling smaller for immigrants? Labour Economics. 2008;15(6):1317-1340. ISSN: 0931-6558

12. Batalova J, Fix M, Creticos P. Uneven Progress: The Employment Pathways of Skilled Immigrants in the United States. Washington, DC: Migration Policy Institute; 2008.

13. Thomas KJ. Occupational stratification, job-mismatches, and child poverty: understanding the disadvantage of Black immigrants in the US. Soc Sci Res. 2015;50:203-216. doi:10.1016/j.ssresearch.2014.11.013

14. Benedict $\mathrm{O}$ and Ukpere W. Brain drain and African development: Any possible gain from the drain? Afr J of Bus Mgmt. 2012;6(7): 2421-2428. doi:10.5897/AJBM11.2385

15. Zimbudzi E. Stemming the Impact of Health Professional Brain Drain from Africa: A Systemic Review of Policy Options. J Public Health Afr. 2013;4(1):e4.doi:10.4081/jphia.2013.e4

16. Drame I, Connor S, Hong L, et al. Cultural Sensitivity and Global Pharmacy Engagement in Africa. Am J Pharm Educ. 2019;83(4):7222. doi:10.5688/ajpe7222

17. Gelayee DA and Mekonnen GB. Pharmacy students' provision of health promotion counseling services during a community pharmacy clerkship: a cross sectional study, Northwest Ethiopia. BMC Med Educ. 2018;18(1):95. doi:10.1186/s12909-018-1216-

18. Adekep OA, Adesuvi BF, Takon JG. Barriers to Healthcare among African Immigrants in Georgia, USA. J Immigr Minor Health. 2018;20(1):188-193. doi:10.1007/s10903-017-0549-9

19. Consedine NS, Tuck NL, Ragin CR, Spencer BA. Beyond the black box: a systematic review of breast, prostate, colorectal, and cervical screening among native and immigrant African-descent Caribbean populations. $J$ Immigr Minor Health. 2015;17(3):905-924. doi:10.1007/s10903-014-9991-0

20. Wilson RT, Watson E, Kaelin M, Huebner W. Early Preparation and Inspiration for STEM Careers: Preliminary Report of the Epidemiology Challenge Randomized Intervention, 2014-2015. Public Health Report. 2018;133(1):64-74. doi:10.1177/0033354917746983

21. Eddy S and Hogan KA. Getting under the hood: how and for whom does increase course structure work? $C B E$ Life Sciences Education. 2014;13(3):453-468. doi:10.1187/cbe.14-03-0050

22. Gavassa S, Benabentos R, Kravec M, Collins T, Eddy S. Closing the Achievement Gap in a Large Introductory Course by Balancing Reduced In-Person Contact with Increased Course Structure. CBE-Life Sciences Education. 2019;18(1). doi:10.1187/cbe.18-08-0153

23. Stolte S, Scheer S, Robinson E. The reliability of non-cognitive admissions measures in predicting non-traditional doctor of pharmacy student performance outcomes. Am J Pharm Educ. 2003;67(1). doi:10.5688/AJ670118 
24. Breslow R. A comparison of academic performance of off-campus nontraditional PharmD students with campusbased PharmD students. Am J Pharm Educ. 2005;69(1). doi: 10.5688/aj690108

Table 1. Descriptive Characteristics of Students Enrolled in a Nontraditional Doctor of Pharmacy Degree Program, $\mathrm{N}=81$

\begin{tabular}{ll}
\hline Variable & $\mathrm{n}(\%)$ \\
\hline Age, Mean (SD) & $47.6(7.5)$ \\
Gender & $38(46.3)$ \\
Male & $43(52.4)$ \\
Female & \\
Region & $9(11.1)$ \\
Midwest & $13(15.9)$ \\
Northeast & $53(64.6)$ \\
South & $5(6.1)$ \\
West & $1(1.2)$ \\
Non-U.S. & \\
Ethnicity & $39(47.6)$ \\
African American & $15(18.3)$ \\
International African & $13(15.9)$ \\
Asian & $14(17.1)$ \\
White & \\
Residency & $56(68.3)$ \\
U.S. Citizen & $25(30.9)$ \\
Non-U.S. Citizen & \\
Pharmacy Related Work Experience & $47(57.3)$ \\
Community & $20(24.4)$ \\
Hospital & $9(9.9)$ \\
Other & $6(7.3)$ \\
Unemployed & $3.44(0.45)$ \\
GPA in Nontraditional Degree Program, Mean (SD) &
\end{tabular}

Table 2. Mean Grade Point Average in the Nontraditional Degree Program by Student Characteristics

\begin{tabular}{ll}
\hline Variable & GPA, Mean (SD) \\
\hline Age & \\
Up to 40 & $3.55(0.37)$ \\
41 to 50 & $3.46(0.49)$ \\
51 and over & $3.35(0.42)$ \\
Gender & \\
Male & $3.44(0.38)$ \\
Female & $3.45(0.5)$ \\
Region & \\
Midwest & $3.23(0.76)$ \\
Northeast & $3.56(0.28)$ \\
South & $3.44(0.43)$ \\
$\quad$ West & $3.61(0.36)$ \\
Ethnicity & \\
African American & $3.31(0.51)^{\mathrm{a}}$ \\
International African & $3.75(0.26)$ \\
Asian & $3.36(0.36)$
\end{tabular}


White

Residency

U.S. Citizen

Non-U.S. Citizen

Pharmacy Related Work Experience

Community

Hospital

Other

Unemployed
$3.54(0.32)$

$3.37(0.46)$

$3.62(0.37)^{\mathrm{b}}$

$3.48(0.49)$

$3.43(0.41)$

$3.35(0.36)$

$3.41(0.48)$

Notes: GPA=Grade Point Average; $\mathrm{SD}=$ Standard Deviation, U.S.=United States

${ }^{a}$ Statistically significant difference between African American and International

African via ANOVA test with Bonferonni used for post hoc comparisons

${ }^{\mathrm{b}}$ Statistically significant difference between United States Citizen and Non-

United States Citizen via ANOVA test with Bonferonni used for post hoc

comparisons

Table 3. Linear Regression Model of Factors Predictive of GPA during the Nontraditional Degree Program

\begin{tabular}{llll}
\hline Variable & $\mathrm{B}$ & Standard Error & $\mathrm{p}$ value \\
\hline Constant & & & $<.001^{\mathrm{a}}$ \\
Northeast Region & 3.55 & 0.43 & .12 \\
South Region & 0.33 & 0.21 & .76 \\
West Region & 0.06 & 0.18 & .49 \\
Male Gender & 0.22 & 0.33 & .39 \\
International African & -0.10 & 0.12 & $.01^{\mathrm{a}}$ \\
Asian & 0.39 & 0.15 & .86 \\
White & 0.03 & 0.17 & .14 \\
United States Citizen & 0.24 & 0.16 & .10 \\
Community Pharmacy Background & -0.22 & 0.13 & .99 \\
Hospital Pharmacy Background & -0.002 & 0.18 & .57 \\
No Pharmacy Career & -0.12 & 0.20 & .93 \\
\hline U.S.-Unicy Str. R-0.237;andica
\end{tabular}

U.S. $=$ United States, $\mathrm{R}=0.237$; a indicates $\mathrm{p}$ value $<.05$ 